\title{
Governing the science of selection: the psychological sciences, 1921-45
}

\author{
Alice White
}

\section{Can leaders be picked and if so, how? ${ }^{1}$}

During the Second World War, this deceptively simple question caused a furore, with heated debates in Parliament and letters to the editor in most major newspapers; everyone from the clergyman to the schoolmaster weighed in on the subject. ${ }^{2}$ As well as those from these established professions, those working in the field of psychological science sought to have their voices heard on the matter: psychiatrists and psychologists argued that their study of human science gave them the expertise to help govern who was best suited to perform the role of leadership. After years of working in industrial management they made the case that their work had relevance for the British military. This case was eventually accepted, and psychological science was given a role in establishing methods of selecting men for roles in conjunction with each of the armed forces. This chapter examines how emergent expertise in psychological science was forged in the armed forces, and how psychological scientists attempted to create a space for their expertise, working within and without military systems of governance to shape scientific and non-scientific practices concerning leadership.

The psychologists and psychiatrists who worked with the military would have to prove not only their specialised knowledge, but also its operative nature; knowledge had to be put to work and to be proved as useful to its patrons in order for it to become expertise. ${ }^{3}$ In his analysis of the historical phenomenon of expertise, Eric Ash notes that Pierre-Paul Riquet, who came to be considered an early modern expert in canals, presumably had knowledge and 
confidence in his abilities that pre-dated his proposal to construct a canal, but that 'his expertise only became tangible - in effect real - once [he] had marshalled it into productive use in the monarch's service'. As with the psychological scientists, is unclear at exactly what point they became 'experts' in governance, but by the end of the war, having seemingly delivered on their promises to control knowledge and innovate, they were clearly considered to fit this definition. ${ }^{4}$

Psychologists' early claims to expertise faced resistance, though; in proposing to choose leaders 'objectively', based on their minds rather than their status, psychologists represented a threat to traditional, class-based systems, which were strongly represented in the military and, particularly, in the Army. Those who developed methods of allocating men to roles and to measuring and picking out leaders implicitly made a statement about who was most suitable to govern, and what form that governance should take. The battle that was played out between the traditionalists and the scientists in the military was a microcosm of that in British society more generally between those advocating for the preservation of conservative systems and those favouring a liberal meritocracy.

The military, particularly during a time of 'total war', also presented a microcosm in the sense that it offered unprecedented opportunities for those in the psychological sciences to experiment in a securely funded, ordered military 'laboratory' where experiments might be conducted that held relevance for society as a whole. In most instances, psychologists' collaborations with the military would last only until the conclusion of the war. However, groups such as the Tavistock would take lessons learned in wartime and apply them to society more broadly in the post-war period, where more slowly established links with industry would prove to have greater endurance, if not such vast scope and funding.

\section{Governing work}

From the turn of the century, attempts had been made to expand the boundaries of the psychological sciences from the study of the peripheral deviant, the insane, to the central matters of everyday life such as matters of employment. The study of selection was approached from a number of psychological lineages. ${ }^{5} \mathrm{~A}$ brief examination of three institutions during the interwar period pre-

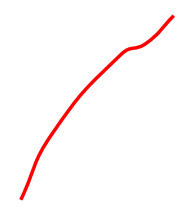


sents a point of comparison for analysing how governance was shaped, the different paths that led to interaction with structures of governance and the subjects of their science.

Some, such as Sir Frederic C. Bartlett and his experimental psychology colleagues at Cambridge University, were academics associated with developing theoretical techniques, who preferred to pursue 'pure' experimental laboratory science. Before the First World War, Bartlett had worked at Cambridge under Charles S. Myers, who had secured the money for the first experimental psychology laboratory in the country, and W.H.R. Rivers. ${ }^{6}$ Both of his seniors then went to work for the Royal Army Medical Corps, but Bartlett was unfit for military service and thus became 'caretaker' of the laboratory, teaching and publishing on a number of topics, including The psychology of the soldier. In this text, Bartlett encouraged men to govern themselves as well as their subordinates, noting 'that a leader should take trouble to know his own character and capacity, and understand clearly what it is that maintains his own authority over his men'. ${ }^{7}$ Bartlett's statement about the benefits to the leader of learning psychology reflected an understanding of psychological science as providing general laws, the learning of which could achieve self-improvement, a tradition dating back to the 1859 book Self-help. ${ }^{8}$

Following the war, Myers departed from Cambridge. Rivers returned 'full of general schemes and activity', but died suddenly in 1922, leaving Bartlett as the permanent custodian of the laboratory. He developed Rivers' plans and contributed his own, growing the department into a respectable part of Cambridge University: a Chair of Experimental Psychology was established in 1931, and Bartlett had three lecturers assisting him by $1933 .{ }^{9} \mathrm{He}$ was elected a Fellow of the Royal Society in 1932. Bartlett followed the established paths legitimating science by engaging in experiments within an academic institution, publishing findings, achieving recognition from scientific governing bodies like the Royal Society and generally operating within the traditionalist structures of internal scientific governance. After departing from Cambridge, Myers took an almost diametrically opposed approach to Bartlett's; he established the National Institute of Industrial Psychology (NIIP), an organisation oriented towards applying psychology in industry. Bartlett considered that 'practical interests' had diverted Myers 'from what might have been a brilliant experimental career'. ${ }^{10}$ 
State involvement in governing management in industry had begun at the end of the nineteenth century, with the passing of the Factory and Workshop Acts. The earliest regulations dealt with physical health and the ages of workers and their hours of work, but from 1901 legislation was 'also directed against the evils of "sweating", condemned alike by 'the best class of employers of labour and by social reformers'. ${ }^{11}$ This move against demanding hard work for low wages as well as towards providing a 'healthy' workplace presented opportunities for the psychological sciences to find a niche in industry, promoting rationalisation of manpower as an alternative method of ensuring output but meeting welfare requirements. Colonel E.G. Wace attempted to introduce similar scientific direction of manpower during the First World War, with limited success. Although he had the support of the Army, which put him in command of the new Directorate of Labour in 1917, junior officers 'could not resist the temptation to depart from strictly outlinelstructures and schedules'. ${ }^{12}$

Increased scientific governance of the workplace was further promoted at the end of the First World War when, shortly after the dissolution of the Health of Munition Workers' Committee in July 1918, the Home Office encouraged the Medical Research Committee (now Medical Research Council) and the Department of Scientific and Industrial Research to appoint the Industrial Fatigue Research Board. ${ }^{13}$ The NIIP 'came into existence in 1921, partly in order to apply the principles set forth by the Industrial Health Research Board' and in part to remedy the problems that Myers saw in society. ${ }^{14}$ It asserted its scientific credentials through some of the traditional society links, beginning with Myers' procurement of industry contracts by giving lectures at the Royal Institution, where the science was targeted at its potential consumers. To circumvent the resistance that Wace had encountered, the NIIP more explicitly promoted the benefits of using its science to govern a workplace, aiming to 'promote by systematic scientific methods a more effective application of human energy in occupational life and a correspondingly higher standard of comfort and welfare for the workers'. ${ }^{15}$

Members of the NIIP worked as consultants, their programme of work focusing upon vocational guidance, studies of temperament and motor ability and studies of influences upon occupational choices and efficiency. ${ }^{16}$ This work followed a tradition of studies 
which looked at workingl through a mechanical metaphor; one proponent claimed, for instance, that 'scientific management as applied to workmen moves with the smoothness of a well-oiled and perfected machine, in which each one performs his part with the accuracy of a mechanically and mathematically perfect tooth on a gear wheel, when it meshes with the teeth of another wheel in transmitting power'. ${ }^{17}$ As this claim suggests, issues of power were built into this science, with self-governance informed by science seen as a positive step by some, who saw 'qualities of individual character as key determinants of social possibility' and therefore the ability to measure and manage character as liberating. ${ }^{18}$ Many people, adolescents particularly, sought out the NIIP's vocational services. Others were critical of the transmission of power up towards owners and managers and away from an increasingly de-skilled workforce. Experiments comparing allocations of boys based on psychological methods with selection based on old management style 'showed the clear superiority of the former', with the scientific approach seeming to trump the 'common sense' knowledge of masters who had known the boys for some time. ${ }^{19}$ In this case, it was the middle management whose claimed expertise was usurped in favour of scientific governance.

Cambridge had its laboratory, the NIIP was in the workplace; but before the Second World War, the psychiatrists affiliated with the Tavistock Clinic remained in the clinic. Like the NIIP, the Tavistock Clinic was set up in 1920, as a response to social problems such as shell-shock, by neurologist Dr Hugh Crichton-Miller, who aimed to provide care to those of limited means. Although they were engaged in work with the National Council for Mental Hygiene (which aimed to focus on promoting well-being as well as curbing mental illness), psychiatrists found it more difficult than their psychological compatriots during the interwar period to expand beyond a perception of their work as associated with mental illness, deviancy and taboo. Psychologist Millais Culpin noted that few doctors would mention an interest in analysis 'without the verbal equivalent of spitting three times over the left shoulder, and even to speak about the revival of war memories carried the risk of being accused of advocating free fornication for everyone'. ${ }^{20}$ The Tavistock Clinic initially had difficulty even in securing premises because of landlords' fears that its would be dealing with 'wildly disturbed lunatics!'21 It had made efforts to obtain academic 
recognition, but with limited success, and had problematic relations with the British Psycho-Analytical Society, the official body of its discipline, because of disagreements over how closely to follow Freud. ${ }^{22}$ In the 1930 s, the Tavistock continued to primarily work with individuals and their problems, although it did embark on a methodological expansion, with funding and recognition from the Rockefeller Foundation, training medics and social workers in how to incorporate psychological techniques into their working practices. $^{23}$

The psychological scientists thus complicate historian David Edgerton's call for twentieth-century history of science to focus on 'regular work' las opposed to outsiders, because even a single institution could operate both within and without government-funded hierarchies. ${ }^{24}$ Much of the work outside of academia was not published, either because of corporate sensitivity or patient confidentiality, or because acquiring the relevant expertise was seen as requiring training or analysis. Yet links with established scientific bodies were utilised to lend legitimacy to work by establishing its scientific nature. Although pursuing different methods of doing so, the Cambridge laboratory, the NIIP and the Tavistock all claimed to investigate the underlying processes of the mind, and to produce from this a distillation of theory and the ability to quantify and potentially control; psychologists offered the armed forces the promise of fundamental knowledge that could help them to innovate and improve their systems of governing men. ${ }^{25}$

\section{Establishing collaborations and governing leadership}

The academic laboratory, the factory and the clinic had become established as legitimate sites for the psychologists' and psychiatrists' work during the interwar period; however, the relationship between the scientists and the military was far more turbulent. Dramatic and fast-paced change occurred over the course of the Second World War, during which each of these psychological institutions, with their differing approaches to matters of selection, developed a relationship with a branch of the British armed forces. Those who had taken the traditional route to scientific credibility via the academy, the Cambridge psychologists under Bartlett, worked with the force that attracted the highest grade of men, the Royal Air Force (RAF). The NIIP worked with the Royal Navy. 
The Tavistock, which deviated from traditional measures and practices of scientific credibility, worked in association with the "hidebound' British Army. The approaches deployed and the respective relationships of these institutes with the forces reveal the role of factors such as culture and social networks in shaping governance of science and governance by science.

Despite psychological scientists' work in industry in the interwar period, their expertise was looked on with contempt by many. The matter of how and by whom men should be governed was lent a greater urgency by the tide of war; Blitzkrieg and the impressive, rapid expansion and success of the Luftwaffe suggested that Germany was organising its men effectively, and that Britain, in retreat, was not. After the various collaborations with the military arms had been set in motion, the scientists developed methods of selection for their respective forces. The scientists' own views of what governance should entail were illuminated through the creation of tests and theories, and the varying relationships that the different scientists negotiated with the military reflected their experiences of science practices in the civil world.

\section{Experimental psychologists of Cambridge and the RAF}

Perhaps because the aeroplane was seen as such a modern and complex technology, selection was incorporated into the RAF earlier than in any other force. The RAF had not pursued the aviation psychology developed during the First World War, and had no selection techniques beyond interviewing at the outbreak of the Second World War. By early 1940, however, tests were introduced under the supervision of the Cambridge University Psychology Department, where Women's Auxiliary Air Force (WAAF) personnel were trained to carry out the testing. Despite this early adoption, Vernon and Parry noted, the introduction of selection in the RAF 'was more gradual and less unified than in either the Army or Navy'. ${ }^{26}$

Psychological tests based upon 'skills' were perceived as operating in the domain of science, and proved to be uncontroversial. As early as the First World War publication The psychology of the soldier, Bartlett had noted that in the military 'the groups with which we are concerned, in any case, all possess a firmly established and finely graded system of official leadership. They are already at

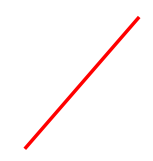


the stage at which leadership as an institution is able to take over some of the functions and authority of the leader as a person. ${ }^{27}$ He believed that whilst a knowledge of a man's skill was useful, it was not crucial, as the institution had sufficient ability to govern its men: they would do as commanded by someone who represented the prestige of the RAF, so the role of individual leaders was less important. The results of the Second World War RAF intelligence tests were 'available for the guidance of board presidents, but no cut-off levels were laid down', echoing the assumption that the institution was free to take or leave scientific guidance. ${ }^{28}$ In addition to a fifteen-minute verbal intelligence test, there were a fifteen-minute mathematical test to establish educational level and two fifty-word essays to hint at expression and alertness to current affairs, although little emphasis was placed on this 'subjective' test. The short and simple 'Bartlett Tests' remained the selection procedure for three years and were seen as helping to make the Service 'test-conscious', if not achieving a better fit of men to roles in themselves. ${ }^{29}$ Interview remained the technique by which officers were chosen until Army War Office Selection Board l(WOSB) methods were adopted in 1945 .

Most work was instead focused on more physical aspects of selection: the problems of fatigue and how to use caffeine and amphetamines appropriately 'according to the type of individual ... in correct dosage the dull appeared somewhat brighter, the average was perceptibly enlivened, while the above average who was normally a "live wire" became "hay-wire" with frayed nerves'. ${ }^{30}$ The work, like Bartlett's pre-war work, was defined by the laboratory and a type of psychology very closely linked with the more established expertise of biology. It focused largely upon the limits of men beyond which control was lost, rather than venturing to quantify the capabilities of men. By maintaining the appearance of producing objective science, Cambridge psychology was free of RAF interference; it remained contained within the scientific world rather than attempting to extend its boundaries to encompass governing the social world.

\section{The NIIP and the Navy}

With war on the horizon in 1939, and concerned that their work might be ignored by the forces it could benefit, the directors of the 
NIIP and Tavistock collaborated in promoting their work in a letter offering their services to the War Office. In the spring of 1939, the state did not perceive a need or use for scientific governance of its troops, and the letter remained unanswered. It would be more than a year before NIIP and Tavistock expertise was put to use in military selection.

Selection in the Royal Navy was introduced in 1941, with the establishment of the Senior Psychologists Department of the Admiralty. The primary task of this department was to assist with the selection and allocation of recruits to technical roles. Although the Navy was able to reject four out of five applicants, failure rates for special jobs like torpedomen were high; difficulties with technology were used as a justification for applying scientific management techniques. Most of the qualified personnel were civilians, with eight psychologists provided by the NIIP forming the core: psychologists 'had no executive authority in the Royal Navy, but acted throughout as technical advisers [so] there was far less frustration than is common when Psychologists work ... under non-professional direction'. ${ }^{31}$ This thus maintained a separation between the military state and civilian science, although the application of work was carried out by the Women's Royal Naval Service. As the small number of psychologists suggests, psychological science provided policy and administrative guidance on how to govern, based on its scientific principles, as opposed to taking an active role in the process. Most of the testing staff , numbering 300 at the peak period, had no scientific training before the war, so efforts were made to ensure that methods were 'as simple and foolproof as possible in order to hand them over'. ${ }^{32}$ Selection was eventually expanded to involve support staff in depots, barracks, specialist schools and mechanics.

As with Bartlett and the RAF, the NIIP saw its role as 'supplying the recruiters with factual information on the basis of which they could more effectively decide the suitability or otherwise of candidates'. ${ }^{33}$ Tests included a biographical questionnaire 'to bring out educational and occupational history, leisure interests and experience of leadership', a non-verbal intelligence test, colour-blindness tests and an interview to detect recruits who might need to be referred for psychiatric examination. ${ }^{34}$ Again, no pass-mark was fixed, and the decision was left to those traditionally responsible for governing whether or not to act on the apparently objective 
scientific information with which they were provided. A second round of tests involved further mechanical and mathematical comprehension and spatial-awareness tests, but also took great pains to provide information to recruits on roles via posters, photographs, bulletins, films and sometimes trade test pieces. A talk from a psychologist emphasised to men 'that it was up to every recruit to do the most difficult job of which he was capable, and not merely one which he thought would give him a pleasant time', and emphasis was placed on the individual's choice of role, echoing the ideal that management science was supposed to benefit those governed as much as those governing. ${ }^{35}$ In being provided a choice of role (albeit in conditions of conscription), men were given the opportunity to opt-in and to see psychology as providing increased freedom and democracy.

To the NIIP, leadership was not only a quality desirable in actual leaders but was sought in everyone: 'leadership experience was advantageous, not only among seamen and officer candidates, but in diverse employments ... Scouts, members of Boys' Brigade, and the like, and of organisations such as the A.T.C. and Sea Cadets showed similar superiority. ${ }^{36}$ These measures of leadership, based on experience and involvement in established organisations, were notably similar to what the military already valued and sought, and therefore less threatening than measures of 'potential' that the Tavistock group would implement. However, by the end of the war, the NIIP was also looking to more radical meritocratic measures, noting that tests of aptitude were validated against qualifications, not 'skills on the job', and hoping that the future would 'see the isolation and measurement of some of the special qualities possessed by successful officers and leaders of men, by executives and administrators, by teachers, research workers, salesmen, interviewers, and so forth'. ${ }^{37}$

\section{The Tavistock group and the Army}

The Army had the biggest problems with allocation of personnel, because it had the least governance over who entered its force; unlike the RAF and Royal Navy, which could select their recruits, the Army had to accept anyone deemed medically fit enough. In 1939, the Army Council agreed to experiment with intelligence testing so as to ensure that technical and fighting staff were capa- 
ble. Psychiatrists conducting their own experiments had obtained promising results, and an advisory committee was appointed, one of whose members was Myers, expanding his influence beyond the Navy and working in affiliation with the Tavistock once more. As a result of their recommendations, the Army Directorate for Selection of Personnel (DSP) was created in 1941, with widespread selection testing for all recruits being implemented through the General Service Scheme in summer 1942. In early 1941, unofficial experiments in officer selection were carried out in Edinburgh by the Tavistock staff. They proved particularly adept at infiltrating the bodies which governed the application of selection science, managing to secure support for their new methods of officer selection from the General Officer Commanding, Sir Andrew Thorne (who had been berated by army colleagues as being 'bloody Freud of the British Army!' for suggesting the use of scientific selection), and the influential General Sir Ronald Adam. The psychoanalyst Adrian Stephen, brother of Virginia Woolf, noted that the Tavistock staff 'can teach us something in the way of practical psychology ... in the tactful handling of negotiations'. ${ }^{38}$

By 1942, the public were baying for a change in how men were selected for commission and politicians were echoing their calls. It was considered that the more technical approach to war used by the Germans was beating the 'old school tie' method of governance used in Britain, which chose leaders based on whether they had attended schools in the Headmasters' Conference. ${ }^{39}$ The press also noted the hypocrisy of fighting 'for democracy' with such an undemocratic Army leadership; arguments over how to govern the Army were representative of broader questions of how to govern a nation, or even the world. ${ }^{40}$ With all of this popular support for change, in 1942 the first experimental LWOSBsLwere set up, and by autumn there were more than a dozen. The psychological approach War OfficeS election Boards (WOS Bs)h was successful at fulfilling Ash's criterion of expertise as being knowledge which enabled its patrons to take 'action at a distance'; the principles developed enabled the establishment of boards on the same lines for the Auxiliary Territorial Service and troops abroad in the Middle East, India, Italy and Western Europe. By the end of war, 'some 140,000 candidates had been through the new procedure, of whom 60,000 passed'. ${ }^{41}$

Psychology was co-opted by the British government and the military at a time of crisis, using science to combat problems seen as 
being caused by modern science and technological warfare, and in order to shore up moral claims to a 'good' democratic form of governance. Military interest in scientific methods of governing the forces was contingent upon factors such as the course of the war and the public's perception of military institutions. Yet it also arose as a result of practitioners foreseeing a need and seeking solutions to problems before they were officially raised, placing themselves in the natural position to enter the military organisational machine when eventually solutions were sought. It took different forms according to the specific different needs of the forces commissioning the collaboration and the involvement of individuals within those forces. These different forms were informed by the theories and practices of the scientists and their attitudes towards the organisation.

As with Navy selection, the selection staff were mainly auxiliary military personnel, but unlike in the Navy the scientists were not self-governing civilians, but located within the hierarchy of the Army, in the ambiguous space of medics in the Royal Army Medical Corps (RAMC), 'mainly because it was thought that only a scheme run by soldiers would be acceptable to soldiers'. ${ }^{42}$ At the peak period there were nineteen psychologists (five women), thirty-one officers with some training, and nearly 600 non-technical officers and 700 Non Commissioned Officers (of whom about 50 and 200 respectively were women). The lack of scientific training in the governing ranks was specifically noted as problematic, because the low prestige of the scientists meant that 'policies which they advocated as scientifically sound were often rejected, and the methods they devised were often misapplied and misinterpreted by insufficiently trained personnel'. ${ }^{43}$ Scientists complained that intelligent teachers and graduates 'were liable to be put on to cutting the grass' at the whim of a Commissioned Officer, a clear suggestion that their technocratic view of how the Army should be governed was not coming to fruition. ${ }^{44}$ They concluded that:

Presumably the lesson to be drawn is that psychologists cannot expect a complex institution like the Army to accept novel procedures merely on scientific grounds, that gradual education and infiltration rather than the imposition of technically valid methods are needed..$^{45}$

Because of their analytical focus, the psychiatrists working with the Army on the WOSBs saw the organisation itself as being disturbed; 
they treated it as their 'patient' and the subject of their techniques of scientific management. As such, they sought to work more actively with it than the other psychologists had with their respective forces, in order to make the changes to selection something which came from within the Army itself:

It would have been possible to construct a scheme for officer selection in which psychologists and psychiatrists applied their methods to the problem while the Army made use of their results, but to do so would have been to introduce a 'foreign body' into the tissues of the Army which would have provoked an inevitable defense reaction. ${ }^{46}$

The psychological approach was therefore a more active component in the choosing of Army officers, and aimed at a view of the man as a whole, rather than passively presenting objective data on skills that might make a man suitable. The General Service Scheme that applied basic intelligence and mechanical tests to all conscripts encountered few problems of military resistance, but the WOSBs were beset with conflict and renegotiation of the proper role of scientists and science. Intelligence tests were also used in WOSBs, and much was made of the use of non-verbal tests to measure potential rather than what had been attained through education. Unlike in the RAF and Navy, some scores did rule out certain roles and eliminated men from being considered for officer training, excluding those who 'would fall in the middle $40 \%$ of the general Army population and would not therefore, be more intelligent than the average "other rank" soldier'. ${ }^{47}$ The scientists made judgements about what a leader should be, and in the view of this highly educated group, those leading should be more intelligent than those they governed. Likewise, whilst the non-verbal intelligence tests were supposed to be blind to education and it was not supposed to matter whether a man had attended a public school, a preference was expressed for the university-educated man as more widely experienced..$^{48}$

Other tests were designed 'not so much to reveal officer traits (e.g. leadership) or abilities, as to bring out the candidates' social reactions under conditions of strain'. ${ }^{49}$ They included word association, which was used in order to suggest attitudes to others, and anxiety or inner conflict where very short answers or blanks occurred, and Murray's Thematic Apperception Test, which was used to explore unconscious relations to others by getting candidates to describe what was happening in a picture. The most

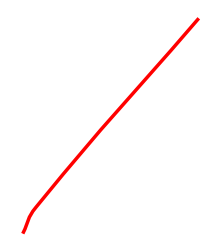


vaunted test developed for WOSBs was the leaderless group test, where candidates were put in groups without allocated leaders and had to complete a task, thus exposing tensions between wanting to do well for oneself and wanting to succeed as a group, and demonstrating the ability of men to manage these tensions. It was considered that the task itself, such as building a bridge, was a disguise for the real psychiatric purpose of the test: observing interaction between men. It may be noted that, unlike the tests used with the RAF and Navy, the outputs of these tests were not quantitative but qualitative. Results were graded on the 'GABI' scale, but this technical name belied a straightforward rating of 'good, average, borderline, inadequate'. The other psychologists were critical of the methodology, but not of the results: 'whether their methods were entirely technically sound or not - they won the confidence of the Army and stimulated a continuous flow of good material'. ${ }^{50}$

Although this approach initially won confidence, problems arose, from the psychiatrists' perspective, from army staff's beginning to act the 'amateur psychiatrist'; they struggled to defend the boundaries of their profession from those who thought that they were equally able to interpret the results of the tests. Similarly, some military men 'found it difficult to accept that an apparently competent man would be rated too low in the intelligence tests for the arm of his choice or when some psychiatric features were uncovered which cast doubts on the man's stability despite an apparently good impression'. ${ }^{51}$ Psychological science faced particular challenges with regard to governance; on the one hand, this science was seen as such common sense that a layman with no training might be able to do it, and on the other hand, it was so bound up in theories that the scientifically untrained could not fathom its conclusions. In focusing to such a large extent on the social rather than 'skills' or reactions to physical stimuli, the psychiatrists were vulnerable to the imposition of outsiders who had their own perceptions of what was being measured. In addition, they were actively involved in decision making. They therefore could be construed as a threat to some members of the Army, who saw them as 'dominating the selection procedure by virtue of their technical knowledge and ability to present evidence', threatening traditional authority with scientific authority. ${ }^{52}$ 


\section{Conclusion}

At the beginning of the Second World War, psychological science claimed expertise relevant to governance of the armed forces, based upon a comprehension of underlying processes in leadership and theories distilled from this. Each institution aimed to establish the legitimacy of its science as a way of rendering human character visible, quantifiable and thus governable, and often pursued similar methods of achieving this legitimation, such as publications and links with scholarly societies and government committees. Pre-war concepts about how science should work in relation to an organisation carried over into the military collaborations of the Second World War, shaping the psychologists' view of the objects of their science, as well as how they themselves fitted into structures of governance. The more closely the psychological approach was engaged with the object of study, the more active the governing role they sought to negotiate for themselves with the military during war. The Cambridge psychologists continued to experiment and produce data, focusing on producing general principles of their science, with little concern about its application by those who paid for it. The NIIP acted as it had as industry consultants, offering tests to govern and methods of easing their acceptance by those to whom they were applied, although ultimately not making judgements about what form governance should take. The Tavistock, by contrast, viewed the organisation itself as a poorly functioning organism, and sought to work with it as a psychiatrist would with a patient in order that it should recognise its failings and implement more long-term improvements.

By establishing the operative nature of their work, psychologists built their expertise over the course of the war. After the war ended, the Tavistock group was able to codify its expert status, establishing the Tavistock Institute of Human Relations to continue work in this field. This organisation found employment in both private and newly nationalised industry, and increasingly found legitimation through publication and academic links. The war had also opened up new avenues for the experimental psychologists at Cambridge. In 1944, an Applied Psychology Unit was established at Cambridge, and Bartlett embarked upon 'a line of investigation on complex human abilities', which some consider to be his 'most outstanding' work, culminating in his monograph, Thinking (1958). ${ }^{53}$ Myers passed away shortly after the end of the war, but 
the NIIP continued in its work. In the 1950s, under the directorship of C.B. Frisby, the NIIP shifted its focus from practical application to science, for instance by seeking status as an industrial research association in order to 'encourage and develop the science of industrial and Occupational Psychology'. ${ }^{54}$ This organisation would expand further in the 1960s, with support from the Ministry of Technology. Beyond these institutions, however, the role of psychological expertise in governance had been established more generally during the war years; in 1950, the civil service category of 'Psychologist' was established, integrating psychological knowledge into the formal governance of Britain. Ironically, applicants were not required to undergo a rigorous selection process. ${ }^{55}$

\section{Notes}

1 Henry Harris, The group approach to leadership-testing (London: Routledge and Paul, 1949), p. 1.

2 The 'Letters to the Editor' section of The Times, between 15 and 28 January 1941.

3 For more on the historiography of expertise and the importance of application of knowledge, see the Osiris special issue on this theme, and particularly the introduction: Eric H. Ash, 'Introduction: expertise and the early modern state', Osiris, 25 (2010), 1-24.

4 Ash, 'Introduction', 5.

5 The terms 'psychology', 'psychiatry', and 'psychoanalysis' were not as clearly demarcated during the mid-twentieth century as they have come to be, and the term 'psychology' often used to encompass the latter. Despite this permeable nomenclature, and even somewhat flexible boundaries of practices and theories, institutional groups with different approaches to the psychological sciences can be differentiated.

6 Ben Shephard, Headhunters: the search for a science of the mind (New York: Random House, 2014).

7 F.C. Bartlett, The psychology of the soldier (Cambridge: Cambridge University Press, 1927), p. 138.

8 Samuel Smiles, Self-help (Oxford: Oxford University Press, 2008).

9 D.E. Broadbent, 'Frederic Charles Bartlett. 1886-1969', Biographical Memoirs of Fellows of the Royal Society, 16 (1970), 1-13, esp. p. 3.

10 Geoff Bunn, 'Charlie and the chocolate factory: C.S. Myers memorial lecture', The Psychologist, 14 (2001), 579.

11 Charles E. Musgrave, The Factory and Workshop Act, 1901: its general effect and parliamentary history (London: Effingham Wilson and Alan Stuart, Carthusian Press, 1902), p. 9. 
12 Nicholas J. Griffin, 'Scientific management in the direction of Britain's military labour establishment during World War I', Military Affairs, 42 (1978), 198.

13 R.S.F. Schilling, 'Industrial health research: the work of the Industrial Health Research Board, 1918-44', British Journal of Industrial Medicine, 1 (1944), 145-52, esp. p. 145.

14 'Rationalization and psychology', The British Medical Journal, 1 (1931), 716.

15 Welch and Myers, Ten years of industrial psychology (1932), p. 5, quoted in Bunn, 'Charlie and the chocolate factory', p. 576.

16 H. Ward, 'National Institute of Industrial Psychology, London: its program of research', Journal of Educational Sociology, 4 (1930), 163-6.

17 John Frey, 'The relation of scientific management to labor', American Federationist, 20 (1913), 297, quoted in Maarten Derksen, 'Turning men into machines: scientific management, industrial psychology and the "human factor", Journal of the History of the Behavioural Sciences, 50 (2014), 148-65.

18 Roger Smith, 'Biology and values in interwar Britain: C.S. Sherrington, Julian Huxley and the vision of progress', Past and Present, (2003), 210-42, esp. p. 241.

19 L.S Hearnshaw, A short history of British psychology, 1840-1940 (London: Methuen and Co. Ltd., 1964), p. 278.

20 Frederick Mott, Neurosis and shell shock (London, 1919), p. 131, quoted in Roger Chickering and Stig Forster, The shadows of total war: Europe, East Asia and the United States, 1919-1939 (Cambridge: Cambridge University Press, 2003).

21 H.V. Dicks, Fifty years of the Tavistock Clinic (London: Routledge and Kegan Paul, 1970), p. 14.

22 For more on the early struggles of the Tavistock and this conflict, see Edgar Jones, 'War and the practice of psychotherapy: the UK experience, 1939-1960', Medical History, 48 (2004), 493-510; Pearl King and Riccardo Steiner, The Freud-Klein controversies, 1941-45 (London: Routledge, 2005).

23 Dicks, Tavistock Clinic.

24 David Edgerton, Warfare state: Britain, 1920-1970 (Cambridge: Cambridge University Press, 2006).

25 As with Riquet's canal expertise, the psychologists' expertise was linked with their claims to control over a body of knowledge that could be put to use in new ways. Ash, 'Introduction', pp. 7-8.

26 Philip Ewart Vernon and John B. Parry, Personnel selection in the British forces (London: University of London Press, 1949), p. 68.

27 Bartlett, Psychology of the soldier, p. 138.

28 Vernon and Parry, Personnel selection, p. 69.

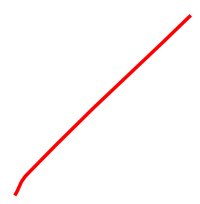


29 Vernon and Parry, Personnel selection, p. 69.

30 Harold E. Whittingham, 'Medical science and problems of flying', The British Medical Journal, 1 (1955), 303-9, esp. p. 305.

31 Vernon and Parry, Personnel selection, p. 28.

32 Vernon and Parry, Personnel selection, p. 28.

33 Vernon and Parry, Personnel selection, p. 29.

34 Vernon and Parry, Personnel selection, p. 29.

35 Vernon and Parry, Personnel selection, p. 31.

36 Vernon and Parry, Personnel selection, p. 138.

37 Vernon and Parry, Personnel selection, pp. 209-10. These groups, which they saw as having special qualities of leadership, are notable for their similarity to the composition of the members of the NIIP, just as the qualities which the Tavistock group would highlight were ones they considered themselves to possess. Those who favoured a continuation of the class-based system of governance and considered the psychologists to be usurpers were right; at the very least, psychologists considered that men very like themselves should lead.

38 Statement made during a Business Meeting of the British PsychoAnalytical Society (1943), quoted in Pearl King, 'Activities of British psychoanalysts during the Second World War and the influence of their inter-disciplinary collaboration on the development of psychoanalysis in Great Britain', International Review of Psycho-Analysis, 16 (1989), 14-33, esp. 17.

39 The Headmasters' Conference was a group of élite, exclusive fee-paying public schools. Examples of politicians' calls for change, with reference to German superiority and the British educational class-system, can be seen in Hansard, 377 (19 February 1942), 1924-99.

40 In particular, the impassioned speech of Thomas Horabin, MP for Cornwall North, Hansard, 377 (19 February 1942),_1924-99.

41 Vernon and Parry, Personnel selection, p. 53; Ash, 'Introduction', p. 16.

42 Vernon and Parry, Personnel selection, p. 41.

43 Vernon and Parry, Personnel selection, p. 42.

44 Vernon and Parry, Personnel selection, p. 42.

45 Vernon and Parry, Personnel selection, p. 42. This suggests the continued relevance in the twentieth century of Ash's contention that in the early modern period, 'the ability to wrangle recognition and favour from political patrons ... could be at least as important as the possession of technical knowledge itself.' Ash, 'Introduction', p. 11

46 J.D. Sutherland and G.A. Fitzpatrick, 'Some approaches to group problems in the British Army', Sociometry, 8 (1945), 205-17, esp. p. 208.

47 Tavistock Archives, Box 205802225, WOSBs Write-Up MSS, p. 16. 
48 As with the NIIP psychologists, the Tavistock group's measures of good leaders (success with intelligence tests, university education) bear notable resemblance to their own qualities.

49 Vernon and Parry, Personnel selection, p. 52.

50 Vernon and Parry, Personnel selection, p. 52.

51 Malcolm Pines, Bion and group psychotherapy (London: Jessica Kingsley, 2000), p. 48.

52 Jeremy A. Crang, The British Army and the people's war, 1939-1945 (Manchester: Manchester University Press, 2000), p. 35.

53 Alberto Rosa, 'Sir Fredrick Bartlett (1886-1969): an intellectual biography' (Department of Psychology, University of Cambridge, 2012).,www.bartlett.psychol.cam.ac.uk/Intellectual\%20Biography. htm (accessed 14 April 2014).

54 Richard Kwiatkowski, David C. Duncan and Sylvia Shimmin, 'What have we forgotten - and why?', Journal of Occupational and Organizational Psychology, 79 (2006), 185.

55 Lara Zibarras and Rachel Lewis, 'What is occupational psychology?', in Work and occupational psychology: integrating theory and practice (London: Sage, 2013), p. 7. 